\title{
1,2, 4-三嗪类化合物的研究
}

\section{VII. $\mathrm{N}^{2}$-[5-(3-甲硫基-6-乙氧羰酰基)-1,2,4-三嗪基]-3- 甲硫基-5-氧代-2，5-二氢-1，2，4-三嗪-6-羧酸乙酯的制 备及其置换反应}

蔡孟深 程铁明朱文君陈文政王少农 (北京医学院药学系)

为系统研究 $1,2,4$ 一三嗪类化合物干扰核酸代谢的规律, 曾经研究了一些三嗪类化合物 的制备及其性质 ${ }^{[1-6]}$.

李钧 ${ }^{[1,2]}$ 等初次发现 6-甲基-3-甲硫基-5-羟基-1,2,4-三嗪（I）在无水吡啶中，与对甲苯 磺酰氯作用,直接滤得 N-[5-(3-甲硫基-6-甲基)-1，2，4-三嗪基] 氯化吡啶嗡盐 (II), II 在微 量吡啶催化下，经水分解得产物推论为 $\mathrm{N}^{4}$-[5-(3-甲硫基-6-甲基)-1，2，4-三嗪基]-3-甲硫 基-6-甲基-5-氧代-4,5-二氢-1，2，4-三嗪（III). 然后他们研究了 II 的胺解 ${ }^{[4]}$ 和 III 的醇解 ${ }^{[5]}$ 反应性能.

本文报告了用5-羟基-3-甲硫基-1,2,4-三嗪-6-羧酸乙酯 (IV) ${ }^{[3]}$ 代替化合物 (I), 以便进 一步了解上述发现, 并研究该类 1，2，4-三嗪结构中, 当 $\mathrm{C}_{6}-\mathrm{CH}_{3}$ 换成 $\mathrm{C}_{6}-\mathrm{CO}_{2} \mathrm{C}_{2} \mathrm{H}_{5}$ 以后, $\mathrm{C}_{5}-$ [N-(1, 2, 4-三嗪)基]作为离去基的可能性及其反应活性.

当我们以化合物 IV 在无水苯中,于 $10^{\circ} \mathrm{C}$, 在无水吡啶存在下, 与对甲苯磺酰氯反应, 然 后继续加水作用，可以顺利地从苯溶液中获得新化合物，其结构推测为 $\mathrm{N}^{2}$ - [5-(3-甲硫基-6乙氧羰酰基)-1，2，4-三嗪基]-3-甲硫基-5-氧代-2,5-二氢-1，2，4-三嗪-6-羧酸乙 酯 ${ }^{[2]}(\mathrm{V})$ (表 1).

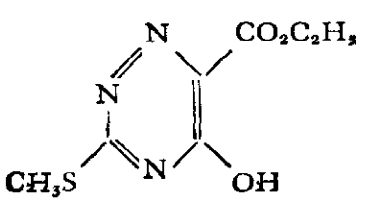

(IV)

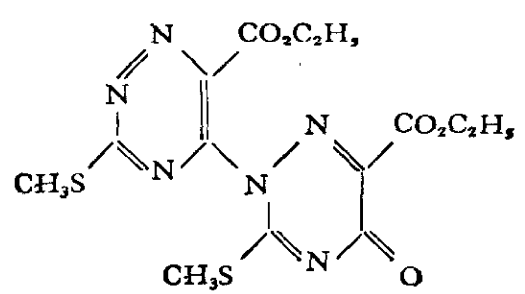

(v)

表 1

\begin{tabular}{|c|c|c|c|c|}
\hline 化合物 & M.P. $\left({ }^{\circ} \mathrm{C}\right)$ & 收率(\%) & $\begin{array}{c}{ }^{1} \mathrm{H}-\mathrm{NMR} \cdot\left(\begin{array}{l}\mathrm{CDCl}_{3} \\
\mathrm{TMS} .\end{array}\right) \\
\delta(\mathrm{pmm})\end{array}$ & 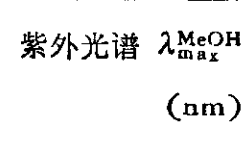 \\
\hline $\mathbf{v}$ & $112-3$ & 60.0 & $\begin{array}{l}1.39(\mathrm{t}, 6 \mathrm{H}) ; 2.63(\mathrm{~s}, 3 \mathrm{H}) \\
2.80(\mathrm{~s}, 3 \mathrm{H}) ; 4.43(\mathrm{~m}, 4 \mathrm{H})\end{array}$ & $\begin{array}{l}247 \text { (肩) }(\varepsilon 17222) \\
284.5(\varepsilon 25771)\end{array}$ \\
\hline
\end{tabular}

本文 1984 年 1 月 7 日收到. 1984 年 4 月 23 日收到修改稿. 
Daunis $^{[7]}$ 报道 3-甲硫基-5-氧代-N-甲基-1，2，4-三嗪-6-羧酸甲酯(VI a,b)的紫外光谱，<smiles></smiles>

(VIa)<smiles>CC(=O)c1nn(C)c(S)nc1=O</smiles>

(VIb)

$244 \mathrm{~nm}(\varepsilon 23500)$

$280 \mathrm{~nm}(85850)$

说明甲基的 $\mathrm{N}^{2}$-和 $\mathrm{N}^{4}$ - 取代对紫外光谱吸收具显著差别，而化合物 V 的紫外光谱与 VIb 相似， 所以推测 $\mathrm{V}$ 为 $\mathrm{N}^{2}$-取代, 而不是 $\mathrm{N}^{4}$-取代.

$\mathrm{V}$ 在无水乙醇中,分别与邻甲苯胺、对硝基苯胺和对硝基苯肼等回流反应 8-16 小时, 即 得到相应的 3-甲硫基-5-取代氨基-1，2，4-三嗪-6-羧酸乙酯 (VII a-c) (表 2). 而当 V 与对 甲苯胺反应时，除得到 3-甲硫基-5-对甲苯氨基-1，2，4-三嗪-6-羧酸乙酯 (VIII) 外，还得到 3-对甲苯氨基-5-羟基-1，2，4-三嗪-6-羧酸乙酯 (IX) 和 3,5-双(对甲苯氨基)-1，2，4-三嗪6-羧酸乙酯 $(X)$ (表 3). 然而当缩短反应时间为 1.5 小时, VIII 的收率可高达 $86.5 \%$ 。

表 2

\begin{tabular}{|c|c|c|c|c|}
\hline $\mathrm{CO}_{2} \mathrm{C}_{2} \mathrm{H}_{5}$ & 化 合 物 & $\mathrm{R}-$ & M.P. $\left({ }^{\circ} \mathrm{C}\right)$ & 收率(\%) \\
\hline & VIIa & o- $\mathrm{CH}_{3} \mathrm{C}_{6} \mathrm{H}_{4} \mathrm{NH}-$ & $121.5-122.5$ & 65.0 \\
\hline 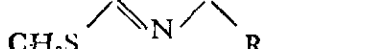 & VIIb & $\mathrm{p}-\mathrm{O}_{2} \mathrm{NC}_{6} \mathrm{H}_{4} \mathrm{NH}-$ & $225-6$ & 59.7 \\
\hline$(\mathrm{VII} a-c)$ & VIIc & $\mathrm{p}-\mathrm{O}_{2} \mathrm{NC}_{6} \mathrm{H}_{4} \mathrm{NHNH}-$ & $255-6$ & 68.6 \\
\hline
\end{tabular}

表 3

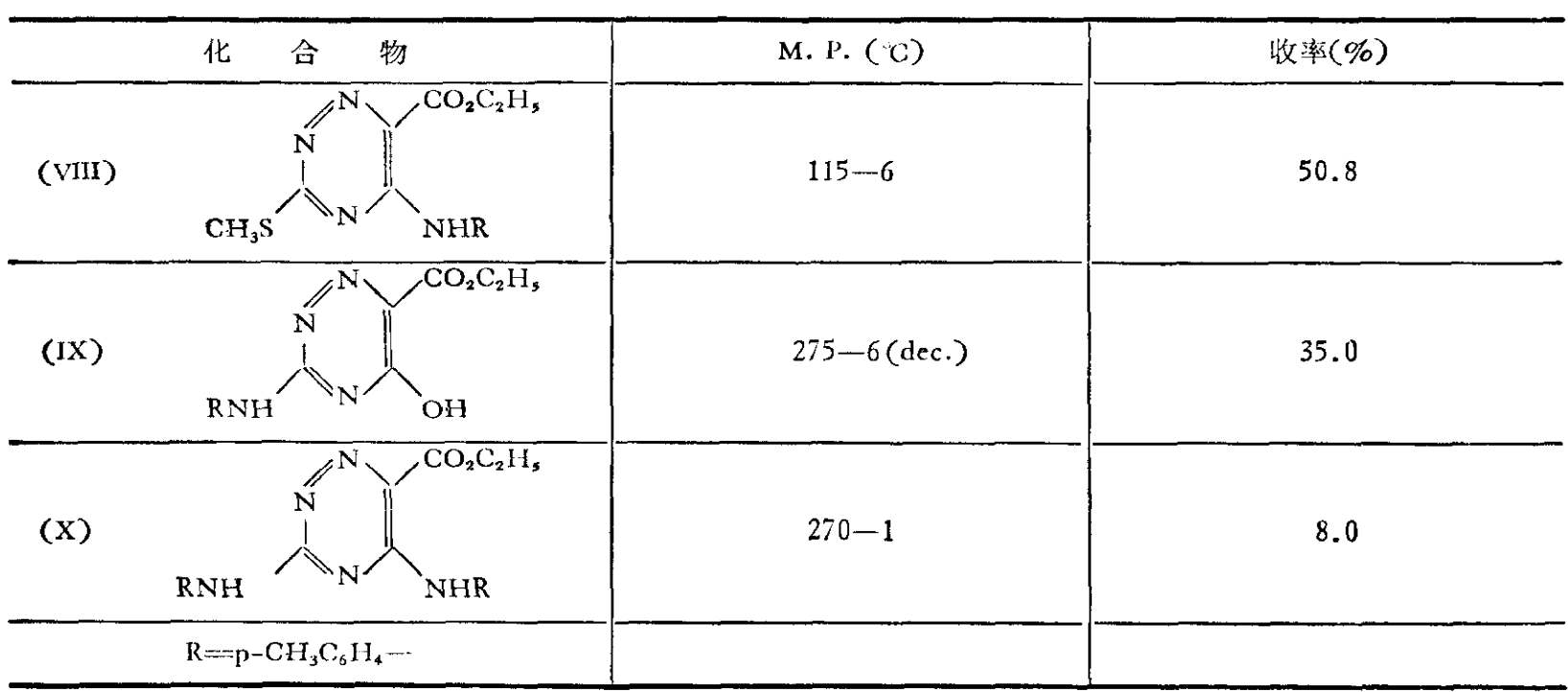

$\mathrm{V}$ 与水合肼 $(90 \%)$ 反应， $-5^{\circ} \mathrm{C}$, 放置四天，生成 $\mathrm{N}, \mathrm{N}^{\prime}$-双 [5-(3-甲硫基-6-乙 氧 羰 酰 基) $-1,2,4$-三嗪基]肼 (XI), 收率 $47.9 \%, \mathrm{M} . \mathrm{P} .232^{\circ} \mathrm{C}$ (dec.). 而化合物 IV 在同样条件下, 则生成 3-甲硫基-5-差基-1, 2, 4-三嗪-6-甲酰肼 (XII ${ }^{[3]}$. 


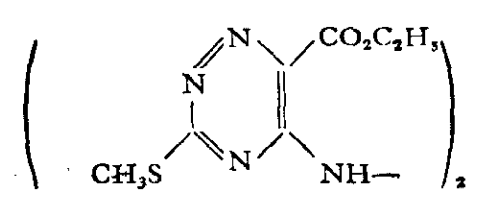

(XI)<smiles>CSc1cnc(C(=O)NN)c(O)n1</smiles>

(XII)

$V$ 在吡啶作用下,于无水乙醇中, 分别与对硝基苯酚、对甲苯酚、对甲氧苯酚、邻甲氧苯酚 及邻硝基苯酚反应, 仅在室温摚拌 2-3 天,即得到相应的化合物 (XIII a-e) (表 4). 但与 2,4二硝基苯酚不反应.

表 4

\begin{tabular}{|c|c|c|c|c|}
\hline & 化合物 & $R$ & M. P. $\left({ }^{\circ} \mathrm{C}\right)$ & 收率 (\%) \\
\hline $\mathrm{CO}_{2} \mathrm{C}_{2} \mathrm{H}$ & XIIIa & $\mathrm{p}-\mathrm{CH}_{3} \mathrm{C}_{6} \mathrm{H}_{4}-$ & 126.5 & 81.2 \\
\hline & XIIIb & $\mathrm{p}-\mathrm{CH}_{3} \mathrm{OC}_{6} \mathrm{H}_{4}-$ & $99-100$ & 44.7 \\
\hline$O R$ & XIJIc & $\mathrm{o}-\mathrm{CH}_{3} \mathrm{OC}_{6} \mathrm{H}_{4}-$ & $100-101$ & 28.1 \\
\hline \multirow[t]{2}{*}{$(\mathrm{XIII} a-c)$} & XIIId & $\mathrm{p}-\mathrm{O}_{2} \mathrm{NC}_{6} \mathrm{H}_{4}-$ & $132-3$ & 59.5 \\
\hline & XIIIe & $\mathrm{o}-\mathrm{O}_{2} \mathrm{NC}_{6} \mathrm{H}_{4}-$ & $90-1$ & 100 \\
\hline
\end{tabular}

综上所述，可以看到在化合物 $\mathrm{V}$ 中， $\mathrm{C}_{5}-\left[\mathrm{N}^{2}-(3-\right.$ 甲硫基-5-氧代-6-乙氧羰 酰 基 $-2,5-二$ 氢）-1，2，4-三嗪基]可作为相当活泼的离去基团,容易发生亲核性置换反应（包括胺解、醇解 反应）;而 $\mathrm{V}$ 中 $\mathrm{C}_{5}$ 的反应活性不仅大于 $\mathrm{C}_{3}$ 位, 而且大于 $\mathrm{C}_{6}$ 位的酯基.

\section{参 考 文 献}

[1] 李钧、张礼和、董振环、王序，化学学报，28 (1962)，167.

[2] 李钧、张礼和、董振环、倪沛洲、王序,化学学报, 29 (1963), 336; 中国科学, XIII(1964), 231.

[3] 王序、蔡孟深、何濑钺、李际和, 化学学报, 30 (1964), 183.

[4] 李钧、王序, 化学学报, 32 (1966), 174.

[5] 李钧、张礼和、王序, 化学学报, 32(1966), 186 .

[6] 李钧、李云贵、王序，化学学报，38(1980), 581.

[7] Daunis, J. et al., Bull. Soc. Chim. Fr., 15i3, 3178. 